\title{
Including the Feedback of Local Health Improvement in Assessing Costs and Benefits of GHG Reduction
}

\author{
Jennifer Chung-I Li ${ }^{1}$ \\ Doctoral Candidate, Dept. of Public Policy and Carolina Environmental Program, \\ University of North Carolina at Chapel Hill \\ Visiting Research Analyst, Trade \& Macroeconomics Division, International Food Policy Research Institute
}

\begin{abstract}
An ancillary benefit of a Greenhouse Gas (GHG) mitigation policy refers to a benefit derived from GHG mitigation that is in addition to the reduction in adverse impacts of global climate change. One type of ancillary benefit of GHG mitigation is reduced local air toxics, which is associated with improved health. Middle-income countries like Thailand are in a position to obtain large ancillary health gains from reduced local air toxics when GHG is mitigated by curbing fossil fuel consumption. Fossil fuel burning has been integral in fueling economic growth but also a major contributor to significant local air pollution in these countries. The highest level of local air pollution is found in heavily populated cities where labor is concentrated and where labor health is believed to have been significantly impacted.

Techniques employed thus far in studying the costs and benefits of addressing GHG emissions in such countries, however, have been inadequate. A review of the existing literature shows that an important local air pollutant, PM-10, is often not included in ancillary benefit analyses for these countries. In addition, the feedback effect of improved health on the economy as a whole has been systematically missing in ancillary benefits studies in general. Previous literature therefore has understated the social welfare benefits of GHG mitigation at least in middle-income countries such as Thailand. This incomplete understanding of the potential benefits of reducing GHG emissions (and through this, air toxics emissions) may have had the policy implication of leading to not enough curbing of GHGs, an inefficient outcome from the perspective of optimal pollution control.

The objective of the current paper is to address these flaws. The paper assesses whether by capturing the local health effects of reduced air toxics as an ancillary effect of GHG mitigation, and by allowing this benefit to feed back into the economy, the desirability of policies aimed at GHG mitigation will change, at least from the standpoint of Social Welfare Benefits. The paper uses a comprehensive cost/benefit framework - a Computable General Equilibrium (CGE) model - for the assessment. A health effects submodel takes the local air emissions output from the CGE model and assesses the implications for ambient air concentration levels, health effects, and ultimately labor supply and medical expenditures. This information is then fed back into the CGE model to find the economy-wide repercussions of the positive effects of the policy through elevated labor supply and reduced medical expenditures. To illustrate this methodology, a carbon tax policy is imposed on a static CGE model calibrated to a 1998 Thai Social
\end{abstract}

\footnotetext{
${ }^{1}$ The author would like to thank Sherman Robinson, Xinshen Diao, and Hans Lofgren at TMD, IFPRI and the Carolina Environmental Program for their financial support.
} 
Accounting Matrix. Findings include: (1) aggregate GDP impact with the carbon tax is lessened by close to $50 \%$ when the feedback effect of health is included compared to not included, and (2) the welfare effect on individual household groups and clean enterprises improve under the scenario with health feedback compared to that without.

\section{Key Words: Greenhouse Gas reduction, Carbon Tax, Local Health Effects, CGE model}

\section{Introduction}

In order to curb GHG emissions, a country needs to reduce fossil fuel use. In this study we examine an economy-wide policy of a carbon tax. The study employs six distinct methodological steps to simulate the feedback of health effects and to assess the influence of this feedback on measures of social welfare used in policy analysis. These methodological steps, shown in Figure 1 below as the boxes are:

1. Specify the policy measure and how it alters specific parameters in subsequent methodological steps used in the assessment;

2. Alter these parameters in the economic model to determine effects on economic indicators of social welfare and on the emissions from economic activity;

3. From the projected emissions, determine the ambient air concentrations and exposures to the resident population;

4. From these exposures and assumed exposure-response relationships, determine morbidity and mortality rates in the resident population;

5. Assess the impact of these morbidity and mortality rates on labor and on health care expenditures;

6. Simulate the economic model again accounting for the labor and health care impacts;

7. Assess the overall economic impact, through the economic model, considering both primary and secondary (feedback) effects; summarize as economic indicators and GHG emissions;

8. Assess the welfare distribution implications of the scenario incorporating the feedback effects and the one without.

The following sections describe the methodology to be used in each of these steps.

Figure 1: Conceptual Framework

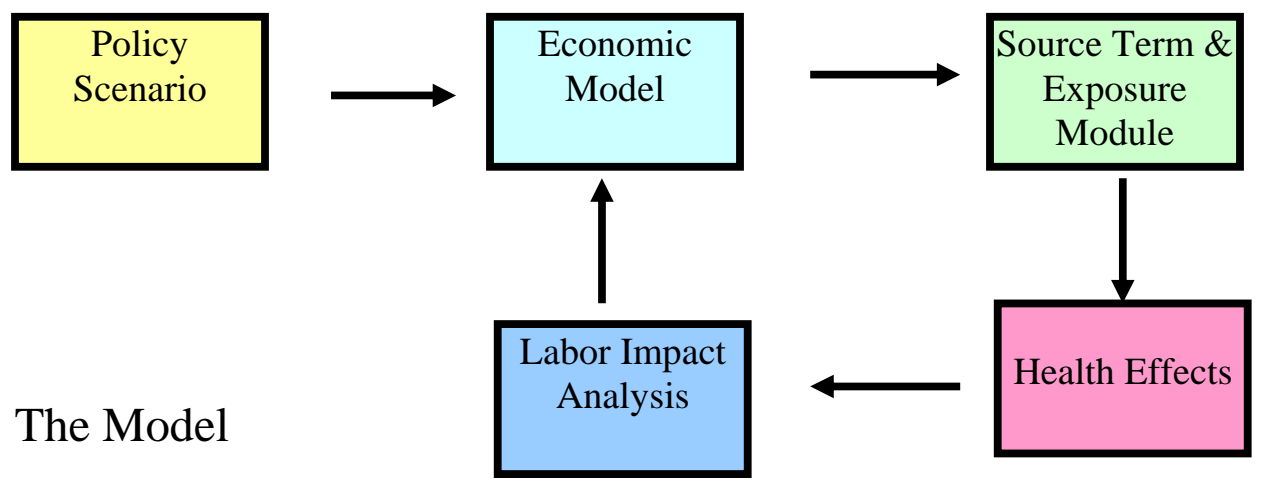

PRELIMINARY DRAFT - NOT FOR QUOTATION OR CITATION 
The model used in this paper is a variation from the "standard model" built by the Trade and Macroeconomics Division of the International Food Policy Research Institute (Lofgren et. al, 2001). The model is calibrated to a 1998 Social Accounting Matrix (SAM) updated from a 1995 SAM by the Thai Development Research Institute (TDRI). TDRI used the following information to update the SAM: Thai National Accounts of $1998^{2}$; current and capital account information which reported external flows data for 1998; the 1998 Thai household income and expenditure survey ${ }^{3}$; and employment and wages data from the 1998 Thai Labor Force Survey. All data sources were reconciled to resolve the inconsistencies among them (TDRI, 2000).

The 1998 SAM obtained for the current study is a more aggregated version of the original 1998 SAM described above. This SAM contains only one type of labor and does not carry detailed employment and wage data. It has 61 production sectors, 3 household categories, and 3 factor types. See Appendix 1 for the model dimension.

The following subsections briefly describe the main characteristics of the model.

\section{Structure of the Economy: Brief Background}

Traditionally dominated by agricultural production, Thailand today has a much more complex and multi-faceted economy. Several important factors have contributed to Thailand's growth. Its principal comparative advantage has been the abundance and diversity of its natural resources. With its agrarian base as the bedrock, the economy has experienced steady growth. In recent years, manufacturing has surpassed agricultural products in Thailand's GNP, while tourism and the related service sectors have replaced agricultural products as Thailand's largest source of foreign exchange (Mahidol University, 1998).

\section{Production}

The production technology for the current model is a nested Constant Elasticity of Substitution (CES) structure taking into account the optimizing behavior in the choice of production factors. Chart 1 in Appendix 2 depicts the nested decision process in the choice of production factors. Starting from the top of the structure downwards; outputs from the three composite goods - non-energy intermediates, energy intermediates, and valued added - are aggregated via Leontief (LEO) technology. The non-energy intermediate aggregate is obtained by combining all non-energy commodities via a CES structure. The labor-capital bundle is also aggregated via a CES structure, allowing a degree of substitution among the factors. The energy composite is a CES aggregate of 8 types of energy that are substitutable: coal \& lignite, petroleum natural gas, gasoline, diesel, fuel oil, aviation fuel, LPG, and electricity. The elasticities of substitution reflect the adjustment possibilities in producers' demand for factors when the relative prices of these factors change.

Income Distribution and Absorption

\footnotetext{
${ }^{2}$ The Thai National Accounts records the aggregate values of final demands and national income.

${ }^{3}$ This survey was used to disaggregate households.
} 
Labor income is allocated to households according to a fixed coefficient distribution matrix derived from the original SAM. Likewise capital revenues are distributed among households, private and public enterprises, and the government. The relative incomes of the three households (Agricultural, Non-agricultural, and Government-employed) are 1:3.47:8.76. On average, government-employed household income is the highest, about 8.76 times that of agricultural household income and about 2.5 times higher than the average income of non-agricultural households.

On the consumption side, private consumption demand is obtained through maximization of household-specific utility function following the Stone-Geary Linear Expenditure System or the Extended Linear Expenditure System(LES) (Lluch, 1973). Household utility is a function of consumption of different goods and saving. The elasticities of household consumption are differentiated by household and product, varying in the range of 0.40 (for basic products consumed) to 2.0 (for services). (Please contact the author if interested in any of the elasticity values used in this study).

The government consumption and investment demands are disaggregated by sector with their shares determined by the data from SAM.

\section{International Trade}

Like most trade-focused CGE models, the model assumes imperfect substitution among goods originating from different geographical areas. ${ }^{4}$ Import demand is derived from a CES aggregation of domestic and imported goods. Export supply is symmetrically modeled as a Constant Elasticity of Transformation (CET) function. Producers allocate their output to domestic or foreign markets in response to relative price changes. For Thailand, the Armington elasticities for demand between domestic and imported products are based on Warr (1998) and informed by the base-year shares of imports, exports, and two-way trade. The transformation elasticities for domestic versus export supply are obtained from Methakunavut and Jitsuchon (2000). The small-country assumption is applied; Thailand is assumed to be unable to change world prices. This specification implies that the import and export world prices are exogenous. Balance-ofpayments equilibrium assumes a fixed value for the current account.

\section{Emissions}

Two types of polluting substances are considered: $\mathrm{CO}_{2}$ and PM-10. An abatement policy targeted at $\mathrm{CO}_{2}$ has the unintended positive effect of reducing a local pollutant, PM-10. ${ }^{5}$ We refer to this secondary reduction of PM-10 as an "ancillary effect" or "ancillary benefit" (Burtraw and Toman, 2000). The association between negative health effects and PM-10 exposure is well-established in the epidemiology literature.

Industries that burn fossil fuels emit $\mathrm{CO}_{2}$ as well as PM-10. PM-10 is also generated during what is called "process emissions" (as opposed to combustion emissions) in the case of cement and construction production where a great deal of dust is

\footnotetext{
${ }^{4}$ Armington (1969).

${ }^{5}$ As well as other local pollutants such as SO2 and NOx; but here we focus on PM-10 alone.
} 
generated. Process-emissions are not related to the amount of fuel used but are related to the total output produced. Another major source of PM-10 is vehicles or final consumption-generated. When a carbon tax is imposed to induce less fossil fuel burning, we therefore do not expect the process-generated PM-10 to drop significantly but should expect the combustion-generated PM-10 (through industrial production and vehicular combustion through internal combustion engines) to drop more.

$\mathrm{CO}_{2}$ emissions on the other hand are emitted through combustion process only, both from industrial production and vehicle use. The following is a summary of the sources of emissions for PM-10 and $\mathrm{CO}_{2}$.

$\mathrm{CO}_{2}: \quad$ production-generated combustion emission, consumption-generated combustion emission

PM-10: $\quad$ production-generated combustion emission, production-generated process emission, consumption-generated combustion emission

Emissions coefficients associated with each intermediate and final consumption for $\mathrm{CO}_{2}$ are derived from the emission coefficients from the U.S. Energy Information Agency. Industry-specific emissions coefficients for PM-10 (for combustion and process-generated emissions) are assumed similar distributions as those applied by Garbaccio et al. (2000) in their study on China.

Formally, the total emission for a given pollutant takes the following form, for $\mathrm{CO}_{2}$ :

$$
E_{C O 2}=\sum_{A} \sum_{E I N P} \alpha_{E I N P} Q I N P_{A, E I N P}+\sum_{I N S T} \tau_{I N S T} C_{I N S T}
$$

$E \quad=$ total emissions.

A $\quad=61$ activity sectors which use energy as an input.

EINP $=8$ energy input categories.

$\alpha=$ emission coefficients for combustion emitted $\mathrm{CO}_{2}$ by sector.

QINP $_{A, E I N P} \quad=$ quantity of each of the 8 energy inputs consumed by each sector.

$\tau=$ emission coefficients for consumption originated $\mathrm{CO}_{2}$ emissions by the final consumer groups or Institutions, households and government.

INST = different institutions.

C $\quad$ INST amount of each polluting good consumed by each institution.

For PM-10, the total emission takes the following form:

$$
\begin{array}{ll}
E_{P M 10}=\sum_{A} \sum_{E I N P} \alpha_{2, E I N P} Q I N P_{A, E I N P}+\sum_{A} \beta_{A} Q D_{A}+\sum_{I N S T} \tau_{2, I N S T} C_{I N S T} \\
\begin{array}{ll}
\alpha_{2} & \text { emissions coefficients for combustion emitted PM-10 by sector. } \\
\beta & =\text { emissions coefficients for the process emitted PM-10 by sector. } \\
\tau_{2} & =\text { emission coefficients for consumption originated PM-10 emissions by } \\
& \text { final consumer groups }
\end{array}
\end{array}
$$


$Q D_{A} \quad=$ total domestic output by activity or sector.

Emissions from production can be reduced in three ways: through a lower aggregate output (the scale effect), a change in the commodity composition (more or less of dirty goods produced, the composition effect), or through the adoption of cleaner technologies (rebalancing the input mix in favor of less polluting inputs, the technology effect). Note that the abatement of consumption-originated emissions could not be achieved through technology effects, since consumption is only composed of final products.

Household utility functions do not include any term directly related to environmental quality. An emission abatement policy will still have utility effects, however, through its effects on consumption and savings. Similarly, environmental degradation does not affect the productivity of production factors. Productivity gains resulting from a greener environment are not measured in this model. The potential gains from environmental protection policies are therefore most likely underestimated.

\section{Linking Expenditures on Health/Medical Treatment to Pollution}

In Thailand, the government and private institutions (insurance and households) are responsible for covering the medical costs. In the case of 'saved' hospital costs due to reduced PM-10, we assume that the government and the household are able to cut back medical expenditure as a result. The use of this incremental income will follow the spending pattern (allocation shares) of the existing government and household accounts.

As alluded to earlier, household consumption behavior is assumed to follow a Linear Expenditure System (LES). To link expenditures (household and government) on medical treatments and health (commodity CHLTHMD) to environmental quality, we specify the consumption of CHLTHMD as follows:

- Having a separate definition for the 'subsistence' level of demand for the medical and health commodity (CHLTHMD) as a function of total $\mathrm{CO}_{2}$ emission and an estimated elasticity of demand $(\varepsilon)$ for CHLTHMD with respect to the $\mathrm{CO}_{2}$ emission level.

- Allocating disposable income to the consumption of "all" commodities, including CHLTHMD.

- By these specifications, we allow the subsistence consumption of CHLTHMD to drop when pollution is lessened (price effect), while allowing the income freed up to be spent on all types of goods (income effect).

With respect to government demand for CHLTHMD, it is separated from government demand for all other commodities. Instead, it is tied to private demand (household demand) for CHLTHMD via the ratio of total government to private consumption of CHLTHMD.

\section{Policy Instruments}


The model includes a variety of pre-existing economic instruments, including: direct and indirect taxes on production, consumption; subsidies on production or consumption; and tariffs and other forms of taxes on imports. With respect to a uniform tax on each unit of $\mathrm{CO}_{2}$ emission, the tax level can be endogenously determined by having an exogenous emission abatement target. Or, one can set the emission tax exogenously and have the model endogenously determine the corresponding emission reduction. For the current paper, the latter approach is adopted. We set the tax rate at a level that would result in a $20 \%$ reduction in total $\mathrm{CO}_{2}$ emissions.

\section{Model Closure}

The equilibrium condition on the balance of payments is combined with other macro closure conditions in order to complete the model. The model includes three macroeconomic balances: the (current) government balance, the external balance (the current account of the balance of payments, which includes the trade balance), and the savings-investment balance.

With regard to government consumption, the model does not capture its direct and indirect welfare contributions; in order to avoid misleading results, it is preferable to keep real government consumption fixed. For the government balance, we also set government savings at a fixed level and allow the direct tax rates of domestic institutions to adjust endogenously. The direct tax rates will be adjusted in a manner that would reflect their pre-policy shock rates paid by various institutions.

For the external balance, the closure sets the real exchange rate flexible while foreign savings (the current account deficit) fixed. Given that all other items in the external balance (transfer between the rest of the world and domestic institutions) are fixed, the trade balance will also be fixed.

Total investment and total savings are set to equal, with savings originating from households, government, and rest of the world. The closure used is investment-driven, which means that the investment quantities are fixed. Under the chosen SavingsInvestment closure, the investment is fixed and the savings rates of selected institutions are scaled so as to generate enough savings to finance investment. Investment is one component of total absorption. The remaining components are household consumption and government consumption. With the nominal absorption shares of investment and government consumption fixed at base levels, the residual share for household consumption is also fixed.

\section{Reference and Carbon Tax Scenario}

The base year of 1998 represents the reference or benchmark economic and environmental scenario in the absence of the environmental policy counterfactual. The impact of the environmental policy is then evaluated against this reference scenario by measuring variations in the economic and environmental aggregates, and the decomposed income distribution effects.

As alluded to before, the environmental scenario considered is a targeted reduction of $\mathrm{CO}_{2}$ emission. The target is set for a reduction of total $\mathrm{CO}_{2}$ emissions (production-generated and consumption-generated combined) by $20 \%$ with respect to the 
reference scenario. The instrument used to reach this target is a uniform tax on energy commodities (used as intermediate and final goods) per unit of emission. The carbon tax receipts are then "recycled" to reduce direct income taxes on all three households as well as the public enterprise. ${ }^{6}$

\section{From the CGE Model to the Health Module}

The carbon tax policy examined appears to have minor costs in terms of output. The GDP is lowered by around $1.2 \%$ with respect to the benchmark, and exports lowered by a higher $2.5 \%$. The reduction in $\mathrm{CO}_{2}$ emission is primarily due to reductions in production-generated emissions. Production-generated emission was lowered by $20 \%$ as a result of the carbon tax whereas consumption-generated is lowered by only $10 \%$. The greater percentage drop can be attributed to the fact that most of the carbon tax burden is on enterprises, and they are the main polluters through their production activities. With the $20 \%$ reduction of $\mathrm{CO}_{2}$ comes an ancillary (unintended) benefit of reduction in PM-10 by $3.72 \%$. This leads to a lowering of the ambient concentration of PM-10, which is beneficial to the health of urban population.

The following section on Health Module further explores the links between total emissions and the ambient concentration of PM-10, and assesses the implications of the change in the ambient concentration of PM-10 to public health and labor productivity.

Linking CGE Outputs to the Health Module:

From PM-10 Emissions to PM-10 Concentration Exposed, the Conversion Links

(See Appendix 3 for an Illustrative Flow-Chart)

The following terms appearing in the methodological steps of Figure 4 are defined:

Source Term PM-10 from Industries before policy

$=S T_{N}^{1}$

Source Term PM-10 from Transportation before policy

$=S T_{N}^{T}$

Source Term PM-10 from Industries after policy

$=S T_{\mathrm{P}}^{1}$

Source Term PM-10 from Transportation after policy

$=S T_{\mathrm{P}}^{T}$

Background Pollution Concentration

$=C_{B}$

Fraction of Ambient PM-10 contributed by Industries

Fraction of Ambient PM-10 contributed by Transportation

$=F_{I}$

Fraction of Time Spent Indoor by an Average Adult

Fraction of Time Spent Outdoors by an Average Adult

Ratio of Ambient Air PM-10 concentration over emissions

rate contributed by Industries

$=F_{T}$

$=F_{I N}^{A}$

$=F_{o U}^{A}$

Ratio of Ambient Air PM-10 concentration over

emissions rate contributed by Transportation/Construction

$$
\begin{aligned}
& =K_{I} \\
& =K_{T}
\end{aligned}
$$

\footnotetext{
${ }^{6}$ See the government closure rule under Model Closure on page 7.
} 
Ambient Air Concentration of PM-10 without policy

$$
\begin{aligned}
& =C_{N} \\
& =C_{P} \\
& =C_{I N} \\
& =C_{I P}
\end{aligned}
$$$$
\text { Ambient Air Concentration of PM-10 with policy }
$$$$
\text { Indoor air concentration without policy }
$$$$
\text { Indoor air concentration with policy }
$$

\section{Estimation of the Dispersion Coefficients, $K_{I}$ and $K_{T}$ :}

In order to translate the actual emissions at multiple origins into the ambient concentration level of the respective pollutant at a specific locality, we need what are called the "dispersion coefficients" which take into account the effects of wind speed and direction, atmospheric turbulence, etc. Usually, these coefficients are obtained using "air dispersion modeling”. For this paper, since we are evaluating a country-wide average concentration level, we decided to assume that the contribution by sources of pollution (industrial, transportation, and background) in terms of ambient concentration of PM-10 after accounting for the air dispersion effects would be similar to the contribution by sources of pollution at origin.

From the Pollution Control Division (PCD) in Thailand, we obtained the information on emission contribution by three sources: point source, line source and area source, corresponding with industrial, transportation, and background emissions. Their respective shares of total emissions emitted at origin (such as at the site of the factories) were reported as $9.78 \%$, 53.94\% and $36.28 \%$ in 1998 .

Assuming the shares of final emissions with air dispersion effects do not depart significantly from the shares of emissions at source; we use 9.78, 53.94, and 36.28 for $F_{I}$, $\mathrm{F}_{\mathrm{T}}$, and $\mathrm{C}_{\mathrm{B}}$. The Source Terms, $\mathrm{ST}^{\mathrm{T}}{ }_{\mathrm{N}}$ and $\mathrm{ST}^{\mathrm{I}}{ }_{\mathrm{N}}$, correspond with total $\mathrm{CO}_{2}$ emissions emitted by the transportation sectors and the industrial sectors. Note that the only "controllable" share of $\mathrm{CO}_{2}$ emissions is therefore about $64 \%$ of total $\mathrm{CO}_{2}$ emissions, assuming that background emissions $\mathrm{C}_{\mathrm{B}}$ is relatively unaffected by the policy. The $\mathrm{ST}^{\mathrm{T}}{ }_{\mathrm{N}}$ and $\mathrm{ST}^{\mathrm{I}}{ }_{\mathrm{N}}$ information is part of the CGE model outputs under the baseline scenario.

With this information, we are able to solve for the Dispersion Coefficients, K's (two equations and two unknowns, $\mathrm{K}_{\mathrm{I}}$ and $\mathrm{K}_{\mathrm{T}}$ ).

$$
\begin{aligned}
& F_{I}=\frac{K{ }_{I} S T_{N}^{I}}{\left(K_{I} S T_{N}^{I}+K{ }_{T}^{T} S{ }_{N}^{T}+C_{B}\right)} \\
& F_{T}=\frac{K{ }_{T} S T_{N}^{T}}{\left(K_{I} S T_{N}^{I}+K{ }_{T} S T_{N}^{T}+C_{B}\right)}
\end{aligned}
$$

We obtained $\mathrm{Ki}=0.000088, \mathrm{Kt}=0.00507$. With these derived dispersion coefficients, we can then assess the Ambient Air Concentration for PM-10 under the baseline scenario through the equation:

$$
C_{N}=K_{I} S T_{N}^{I}+K_{T} S T_{N}^{T}+C_{B}
$$

The first term on the right expresses the contribution from Industry, the second the contribution from Transportation, and the third contribution from "background pollution”. Under the policy scenario, the economic model will provide us with a new 
set of source terms. Using the source term information obtained as outputs from the model under the carbon tax scenario and the level of original ambient concentration $\mathrm{Cn}$, we infer the ambient concentration of PM-10 under the carbon tax scenario, Cp, as follows:

$$
C_{P}=C_{N} \times\left[\left(K_{I} S T_{P}^{I}+K_{T} S T_{P}^{T}+C_{B}\right) /\left(K_{I} S T_{N}^{I}+K_{T} S T_{N}^{T}+C_{B}\right)\right]
$$

With this expression, we assume that the ambient concentration of PM-10 is proportional to the total source term. The indoor air concentration with a policy then is given by Cip $=\mathrm{Cp} x \mathrm{R}$, where $\mathrm{R}$ is the ratio of indoor to outdoor air concentration ( $\mathrm{R}$ is assumed invariant with policy). $\mathrm{R}$ is determined from measurements performed in Thailand. The time-weighted average concentration then equals the weighted sum of the outdoor and indoor concentrations, weighed by the fractions of time spent daily in those two settings. ${ }^{7}$

Based on the observation of the epidemiologist and Professor of Public Health at the University of North Carolina at Chapel Hill, Dr. Dana Loomis, who is familiar with the PM-10 issues in Thailand, the indoor-outdoor concentration of PM-10 in Thailand should not vary by much for two reasons: (1) the fine size of the particulate matter of concern (less than 10 micrometer in diameter) which is better mixed indoor versus outdoor compared to coarser particulates, and (2) the level of air conditioned housing in Thailand is still relatively low, which makes it more likely for windows to be open and air exchange between indoor and outdoor air. Given these reasons, we assume that $\mathrm{R}$ is equal to 1.

Given the baseline ambient PM-10 concentration of around $68 \mu \mathrm{g} / \mathrm{m}^{3}$ for Thailand in 1998 (ADB, 1999), we were able to derive the post carbon tax PM-10 concentration, $\mathrm{Cp}$, using the procedure laid out above to be around $66.8 \mu \mathrm{g} / \mathrm{m}^{3}$.

\section{Exposure-Response model}

Applying the 24-64 age group ERR for PM-10 to our context, with a drop of PM10 concentration by $1.5 \mu \mathrm{g} / \mathrm{m}^{3}$ or $2.2 \%$, we get the following percentage change/reduction in mortality for the 24-64 age group.

$\% \Delta H_{M T}=0.1 * 2.2\left(\mu \mathrm{g} / \mathrm{m}^{3}\right)=0.22$

To translate it into the actual number of deaths attributable to exposure to PM-10 (rather than fractional or percentage change in deaths), for the 24-64 population (around $50 \%$ of total population in 1998), we go through the following procedure:

$$
\begin{aligned}
\Delta H_{M T} & =b \cdot \Delta P M-10 \cdot C M R \cdot P O P / 100
\end{aligned} \begin{aligned}
\Delta H_{M T} & =0.1 * 2.2 *(6.5 / 1000) * 29410375 / 100 \\
& =420 \\
& (261,547)
\end{aligned}
$$

\footnotetext{
${ }^{7}$ According to Pearce (1996a), an average adult in a developing country spends approximately $70 \%$ of his time indoor and $30 \%$ outdoors.
} 
where $\Delta H_{M T}$ stands for the change in the number of mortality cases due to PM-10 exposures in a population (not the percentage change, as in the table above); $b$ is the slope of the dose-response function and equals $0.062,0.1,0.13$ respectively for lower, central and upper bounds (remember that the slope is in percentage change per $\mu \mathrm{g} / \mathrm{m}^{3}$ ). The $\triangle P M-10$ term captures the average change in ambient PM-10 concentration (averaged over some geographic region or population used as the base for the health effects study). CMR is the Crude Mortality Rate for the entire population; applying to all deaths in the respective population exposed in 1998. Here we assume the CMR for the total population is applicable to that for the 24-64 age population.

According to the National Statistical Office of Thailand, the working population in Thailand is defined over a narrower range of 15-59 years of age. ${ }^{8}$ In order to extract the incidence of mortality estimated for the 15-59 range from the 24-64 range, we go through two steps: First for the 24-59 range, we estimate its share out of the 24-64 range (67.9\%) with respect to mortality (all causes) for Thailand in 1998 with data from the National Statistics Office, Thailand. Then for the 15-23 range, we assumed the mortality induced by exposure to PM-10 in this age range is the same as its relative share over mortality (all causes) vis-à-vis the 24-64 age group (around 10\%).

$\Delta H_{M T}$ for the working age group 15-59 then becomes:

$(420 * 0.679)+42=327$

One important feature of the study is that the estimation leaves out long-term chronic effects, e.g. permanent impairment of lung function and the development of diseases such as asthma and chronic obstructive pulmonary disease. This is appropriate given the short-term focus of our study - we consider only the acute effects resulting from short-term exposure to PM-10. More importantly, we are interested in the changes in these effects with the imposition of a carbon tax policy.

For morbidity calculation we are informed by the ERRs for acute illnesses applied to short-term exposure to ambient PM-10 concentration. Table 3 below lists the ERRs used for estimating the change in the cases of hospital admissions due to a change in PM10 concentration after the carbon tax imposition.

Table 3: Exposure-Response Functions for hospital admissions associated with PM-10 in Thailand Health effect category Annual number of cases per person per $1 \mu \mathrm{g} / \mathrm{m}^{3}$ change in annual average PM-10 (probability weight for average PM-10 scenarios in parentheses)

\footnotetext{
${ }^{8}$ (http://www.nso.go.th/gender/epop.htm).
} 
Respiratory hospital admissions

Cardiac hospital admissions
Low: $2.8 \times 10^{-6} \quad(33.3 \%)$

Central: $5.7 \times 10^{-6}(33.4 \%)$

High: $8.5 \times 10^{-6} \quad$ (33.3\%)

Low: $2.8 \times 10^{-6} \quad$ (33.3\%)

Central: $5.0 \times 10^{-6}(33.4 \%)$

High: $7.2 \times 10^{-6} \quad(33.3 \%)$

Source: Chestnut et al. (1998)

Given the change in the ambient concentration of PM-10 by $1.5 \mu \mathrm{g} / \mathrm{m}^{3}$ or $2.2 \%$ and a total population of $60,763,000$, we can proceed to calculate probability weighted respiratory and cardiac hospital admission changes associated with a change in PM-10 concentration using the hospital admission exposure-response relationships for respiratory and cardiac hospital admissions.

Respiratory:

$\Delta H_{R S}=[(0.0000028 \cdot \Delta P M-10) \cdot 0.333]+[(0.0000057 \cdot \Delta P M-10) \cdot 0.334]+[(0.0000085$ $\cdot \triangle P M-10) \cdot 0.333] * 60763000$

$\Delta H_{R S}=757$

Cardiac:

$\Delta H_{R S}=[(0.0000028 \cdot \Delta P M-10) \cdot 0.333]+[(0.000005 \cdot \Delta P M-10) \cdot 0.334]+[(0.0000072$ $\cdot \Delta P M-10) \cdot 0.333] * 60763000$

$\Delta H_{R S}=668$

Again, only a fraction of these applies to the 15-59 working population. Based on NSO data, $44.5 \%$ of total reported illnesses in 1998 can be attributed to the 15-59 population. We apply this percentage to derive the respiratory and cardiac hospital admissions changes induced by a change in the ambient concentration of PM-10 to the 15-59 age group.

$(0.445 * 757)=337$

$(0.445 * 668)=297$

Knowing the mortality and hospital admissions effects of the change in PM-10 concentration, we then want to translate these into on labor supply and medical expenditures impacts.

\section{Labor Impact \& Medical Cost Analysis}

From the former step we derived the change in the incidences of respiratory and cardiovascular illnesses and premature mortality as a result of a change in ambient air concentrations. Policy analysts would often try to quantify the benefits/costs associated with a change in health status. The major economic benefits/costs are labor productivity gains/losses and medical treatment savings/costs due to a health status change. 
With respect to labor change, we use an approach similar to that used by Rosendahl (1998) with "reduced activity days" (RADs).

With respect to medical costs, we use the hospital admission Exposure-Response rate (ERRs) results from the morbidity assessment above, coupled with the average costs information for medical and health costs incurred on each type of hospital admission to estimate total costs saved. The estimation of medical costs is for the purpose of crosschecking the resulted reduction in medical expenditure which is captured endogenously by the CGE model.

\section{Labor Impact Analysis}

For the analysis of reduced PM-10 concentration on labor supply, we assume the change does not apply to rural or agricultural household but applies only to two urban household categories: non-agricultural and government-employed.

The change in labor supply includes permanent and temporary change in the availability of workers at the job. In terms of temporary change, there are two components - the days of work lost (due to sick leaves, hospital visits, etc.) and reduced productivity at work both of which cause a temporary effect on labor supply. In terms of permanent effect on labor, the premature mortality avoided due to lowered PM-10 concentration estimated from the last section will add to the 'baseline' quantity of labor.

To assess the temporary change in labor supply (both days lost and productivity reduction), we will use a dose-response function that links changes in PM-10 concentration directly to the changes in the RADs.

Using the Dose-Response function for RADs for the working age population from 15-59, developed by Ostro (1994), we will go through the following steps:

- 1 unit rise in PM-10 leads to an increase of 0.058 RAD per person per year or 0.00016 RAD per person per day (Ostro, 1994)

- $62 \%$ of all RAD are bed-disability days (100\% productivity loss)

- The other $38 \%$ are Minor RAD or MRAD (10\% productivity loss)

- Multiplying 0.058 by the average wage of the working population, we can get an estimate of the value of work lost per year. The shares of bed-disability days and MRAD can be assessed.

The current policy simulation results in a reduction in PM-10 concentration of 1.5 $\mu \mathrm{g} / \mathrm{m}^{3}$ or a drop by $2.2 \%$. This leads to a saved RAD of $0.1276\left(0.058^{*} 2.2\right)$ RAD per person per year.

Out of this, $62 \%$ are bed-disability days saved, and the rest Minor RAD or MRAD saved.

There are three household types supplying total labor based on the 1998 Social Accounting Matrix for Thailand: Non-agricultural households (HH-NAG), Agricultural households $(\mathrm{HH}-\mathrm{AGR})^{9}$, and Government-employed households (HH-Gov). The

\footnotetext{
${ }^{9}$ Again, we do not assume the labor in this household category is affected by the change in the ambient concentration of PM-10. We provide the average income for this household group here as general information.
} 
average annual incomes for these households in 1998 were 183275.8, 64454, and 177640.

After many steps of calculation, total labor saved (sum of labor gained due to avoided mortality and avoided RAD and MRAD) in terms of wage is estimated to be $1,290,952,484$ baht, which is about $8 \%$ of the baseline. However, note that the DoseResponse rate or ERR used for RAD was estimated for the United States (Ostro, 1994). When applied Thailand, we scale it by the ratio of U.S. Purchasing Power Parity (PPP) to Thai PPP to get the adjusted outcome for Thailand. ${ }^{10}$ The U.S. PPP per capita over the Thai PPP per capita in 1998 equals 5.29 ${ }^{11}$. Dividing the percentage above by 5.29, we then derive the adjusted total labor saved as around $1.5 \%$.

In terms of relative contributions to total labor supply change, pre-mature mortality change contributes a minimal share $(1 \%)$ and the change in RAD contributes the bulk of the change in total labor supply (99\%). This is observed for the labor from both non-agricultural and government-employed labor categories.

\section{Medical Cost Analysis}

Health impairments due to ambient air exposures demand resources through medical treatment as well. When the health effects incidence caused by air toxic exposures declines, the resources originally spent for health treatment can be used for other purposes. Exposure to PM-10 will result in illnesses for which workers will seek hospital care. Reduction in ambient air pollution concentration of PM-10 will, therefore, lower the case of illnesses and lower the medical expenditures component of the CGE.

One way to quantify this impact is by using the hospital admissions ERR. For Thailand, we have calculated the changes in cardiovascular and respiratory hospital admissions due to a change in ambient PM-10 concentration. The results here recaptured are:

Respiratory hospital admissions are lowered by 337 cases:

$\Delta H_{R S}=337$

Cardiac hospital admissions are lowered by 297 cases:

$\Delta H_{C D}=297$

With the ERR information, we will next require hospital data on the mean length of stay $^{12}$ and mean total charge ${ }^{13}$ for the two disease categories: respiratory and

\footnotetext{
${ }^{10}$ Pearce and Crowards (1996b), when applying the same ERR for RAD by Ostro (1994) to UK, scaled it by the ratio of U.S. GDP per capita to UK GDP per capita to get the adjusted outcome for UK.

${ }^{11} \mathrm{http}: / /$ www.worldbank.org/data/wdi2000/pdfs/tab1_1.pdf

${ }_{12}$ Mean length of stay (LOS) is calculated by dividing the sum of inpatient days by the number of patients within the DRG category (Diagnosis-related groups (DRGs) are a classification of hospital case types into groups expected to have similar hospital resource use). Inpatient days are calculated by subtracting day of admission from day of discharge, so persons entering and leaving a hospital on the same day have a length of stay of zero (http://www.ahcpr.gov/data/hcup/94drga.htm)

${ }^{13}$ Mean total charge is calculated by dividing the sum of patient charges by the number of patients within the DRG category. Total charges represent the dollar amount charged for the hospitalization rather than the amount paid or the actual costs to provide the care. Physician payments are not included.

(http://www.ahcpr.gov/data/hcup/94drga.htm)
} 
cardiovascular in Thailand. With these information we can figure out the total medical charges per year for the two respective disease categories. Unfortunately we were unable to find the MLOS and Mean total charge data for Thailand; instead we acquired such information for the U.S. and scaled them by the Purchasing Power Parity per Capita ratio between the U.S. and Thailand to obtain similar information for Thailand.

With 337 as the total number of annual hospital admissions for respiratory diseases attributable to PM-10 exposure and 297 as the total number of annual hospital admissions for cardiovascular diseases attributable to PM-10 exposure; we next obtained the Mean length of stay associated with each of the two types of hospital admissions. After calculation, the numbers are 5.39 for respiratory admissions and 5.37 for cardiac admissions; then we have $337 * 5.39=1816$ total number of bed-days stayed in hospitals for respiratory admissions attributable to PM-10 exposure and 297*5.37= 1597 total number of bed-days for cardiac hospital admissions attributable to PM-10 exposure.

We then need the Mean total Charge for each of the two types of admissions. After calculations, we get the mean 311 baht (US\$1646 in 1998 divided by 5.29) per bed day on average for respiratory admissions and 370 baht (US\$1846 in 1998 divided by 5.29) per bed day on average for cardiovascular admissions; this gives us 601,407 baht of medical costs for respiratory admissions attributable to PM-10 exposures and 590,973 baht of medical costs for cardiovascular admissions attributable to PM-10 exposures. The total medical costs incurred by particulate induced hospital admissions in 1998 in Thailand therefore sum to 1,192,381 baht.

\section{Feeding Back Labor Supply and Medical Expenditure Change into the Economic Model}

Previous studies would normally stop here by reporting the value of the increase/decrease in labor-supply as the health benefits/costs of mitigating GHG. In the paper, however, we feed-back the change in labor supply as well as the change in medical spending information to the CGE model to evaluate the secondary general equilibrium effect of these ancillary benefits and costs.

The change in labor supply (output from the previous step) will lead to an adjustment in the amount of labor in the Primary Factor sector of Labor (an input sector in the economic model). Since the health improvement results in a gain of $1.5 \%$ of labor in value per year, the labor supply (in value term) will be multiplied by a factor of 1.015.

The change in medical expenditures due to a change in total emissions $\left(\mathrm{CO}_{2}\right.$ and therefore PM-10 as an ancillary effect) is automatically taken into account by the model given the model structure which endogenizes the consumption of medical commodity as a function of total pollution emitted and an estimated demand elasticity of medical commodity with respect to total pollution level.

A summary of the size of the various feedbacks: with a $20 \%$ reduction in $\mathrm{CO}_{2}$ we observe an ancillary reduction in PM-10 emissions by 3.72, which is translated into a $2.2 \%$ reduction in the ambient concentration of PM-10. This leads to a $1.5 \%$ increase in total labor supply, applicable only to labor belonging to non-agricultural and government-employed households. A $0.3 \% \sim 2.5 \%$ reduction in the consumption of health and medical services is the other effect of reduced ambient PM-10 endogenized in the CGE model. 


\section{Analysis of Overall Economic Impact}

With the imposition of a GHG mitigation policy such as a carbon tax, the $\mathrm{CO}_{2}$ emitting production and consumption activities are made to "internalize" the private and social costs of pollution emissions. This has varied cost and benefit implications to different stakeholders, some becoming evident over time and others evident immediately after policy imposition. A CGE model is able to capture the direct costs of economic efficiency costs which result in a reduction in GDP; it can also capture the indirect benefits of improved labor health and reduced medical expenditures in the form of an increase in GDP. ${ }^{14}$ Thus a CGE model automatically generates estimates of the tradeoffs between these specific economic benefits and costs and yields the net GDP change. In the proposed project, we are interested in comparing the net GDP change under the Policy scenario vis-à-vis that under the Baseline/no policy scenario. More importantly, we want to compare the net GDP under the 'Policy scenario with Health Feedback' vs. the 'Policy scenario Without Health Feedback'. We hope to see that by including the Positive Health Feedback, the net GDP change would be more positive. By including more fully the benefit side of GHG mitigating policy (such as the health improvement feedback and allowing its effect to play out in the economy), we may see a much more positive effect of GHG mitigating policies on GDP and therefore a more accurate policy advice to middle-income countries like Thailand.

Based on the model outputs, we observe a 45\% less reduction in GDP with the $\mathrm{CO}_{2}$ tax when the feedback is taken into account. With the feedback, we also observe a slightly greater trade composition change: with relatively less reduction in exports/imports of clean goods than that of dirty goods. Aside from the composition effects, with the feedback the carbon tax induces greater input substitution away from polluting energy intermediates and to more factor and non-energy intermediates (technology effect).

The table below captures these differences under the "no feedback" and "with feedback" scenarios

\footnotetext{
${ }^{14}$ The health effects considered the current paper do not include the quality of life benefits associated with environmental risk reduction. Should such valuation data be available, they could be incorporated at the Social Welfare Analysis stage. Not taking into account the quality of life benefits in the policy analysis means we will underestimate the local health benefits of GHG mitigation.
} 
Table 2: Economic Impact Comparison

\begin{tabular}{|c|c|c|}
\hline & Tax Vs. No Policy (baseline) & Tax + Feedback Vs. No Policy \\
\hline - GDP & $-1.2 \%$ & $-0.66 \%$ \\
\hline - Exports (total) & $-2.5 \%$ & $-2.1 \%$ \\
\hline $\begin{array}{l}\text { - Exports of pollution } \\
\text { intensive goods }\end{array}$ & $-2.6 \%$ & $-2.2 \%$ \\
\hline $\begin{array}{ll}\text { - } & \text { Exports of goods } \\
\text { from non-pollution } \\
\text { intensive industries }\end{array}$ & $-0.8 \%$ & $-0.3 \%$ \\
\hline $\begin{array}{ll}\text { - } & \text { Exports of } \\
\text { agricultural goods }\end{array}$ & $-0.5 \%$ & $-0.3 \%$ \\
\hline - $\quad$ Exports of service & $+0.2 \%$ & $+0.7 \%$ \\
\hline - Imports (total) & $-3.4 \%$ & $-2.8 \%$ \\
\hline $\begin{array}{l}\text { - Imports of pollution } \\
\text { intensive goods }\end{array}$ & $-3.7 \%$ & $-3.2 \%$ \\
\hline $\begin{array}{l}\text { - } \quad \text { Imports of goods } \\
\text { from non-pollution } \\
\text { intensive industries }\end{array}$ & $-2.5 \%$ & $-1.6 \%$ \\
\hline $\begin{array}{ll}\text { - } & \text { Imports of } \\
\text { agricultural goods }\end{array}$ & $-2.1 \%$ & $-1.5 \%$ \\
\hline - $\quad$ Imports of service & $-2.6 \%$ & $-2.0 \%$ \\
\hline
\end{tabular}

\section{Social Welfare Analysis}

In addition to examining the aggregate criterion of GDP, it is important to compare the income distribution effects of the policy with and without the health feedback. In terms of health, non-agricultural households, and government-hired households are likely to gain more from a carbon emission reduction policy (as opposed to agricultural households) since the secondary effects of reduced local air pollution will mostly benefit the urban population. However, due to the lack of air dispersion modeling data, we cannot trace location specific pollution change and location specific welfare change in terms of health. We can, however, evaluate income distribution changes as a result of the carbon tax.

In this analysis, the welfare effects are measured using Equivalent Variation $(\mathrm{EV})$, a measure that addresses the question: "What income would be equivalent to the change brought about by introducing a carbon tax?"

The table below reports the welfare effects:

Table 3: Welfare Change Comparison

\begin{tabular}{|l|c|c|}
\hline & Tax Vs. No Policy (baseline) & Tax + Feedback Vs. No Policy \\
\hline Households & & \\
& & \\
(1) Agricultural hhds & $-2.6 \%$ & $-1.8 \%$ \\
(2) Non-Agricultural hhds & $-2.2 \%$ & $-1.0 \%$ \\
(3) Gov't-Hired hhds & $+1.7 \%$ & $+2.4 \%$ \\
\hline Energy intensive industries & $-0.04 \%$ & $-0.03 \%$ \\
Non-energy intensive indus.s & $-0.21 \%$ & $-0.17 \%$ \\
\hline
\end{tabular}




\begin{tabular}{|l|c|c|}
\hline Energy producers & $-0.26 \%$ & $-0.25 \%$ \\
Transportation industries & $-0.03 \%$ & $-0.02 \%$ \\
Agricultural sectors & $-0.023 \%$ & $-0.02 \%$ \\
Service sectors & $-0.01 \%$ & $-0.005 \%$ \\
\hline
\end{tabular}

With respect to effects of the carbon tax on household welfare measured with EV (in nominal value), we see around 50\% less effect of the tax when the health feedbacks are included across household categories. This has already factored in the effect of recycling the carbon tax revenue for reducing income taxes.

Some sectoral welfare distribution information is also provided. Not surprisingly, lower levels of production are observed for most pollution intensive manufacturing sectors ${ }^{15}$ when the tax is imposed. However, the welfare effects of the carbon tax on these and all other sectors are lessened when the health feedback is incorporated.

\section{Conclusion}

Previous literature on ancillary benefits of GHG mitigation policies tends to understate the Social Welfare Benefits by not including the ancillary benefits.

This in part has led to insufficient GHG mitigation in certain countries. These include middle-income countries (e.g., Thailand, Malaysia, Brazil, and China) that have highly polluted mega-cities where their labor forces are concentrated.

This paper considers the question: By capturing the local health effects of reduced air toxics as a secondary effect of reducing GHG emissions, and allowing this benefit to feed back into the economy, do we change the desirability of policies aimed at GHG emissions reduction from the standpoint of social welfare benefits?

The study explored the question when a carbon tax is used to reduce GHG emissions. The results of the study show that when these important ancillary benefits of reducing GHG emissions are captured, we observe the following impacts:

(1) $45 \%$ less impact on GDP

(2) emissions reductions through a 'cleaner' trade composition and more pronounced substitution of energy inputs with non-energy and factor inputs

(3) on average $28 \%$ less welfare effect across household and producer sectors excluding Government-employed household which experiences a net gain in welfare under both scenarios but a 40\% higher gain under the 'with feedback' scenario

Some caveats for the result are necessary. Firstly this paper does not attempt to include all possible secondary effects of GHG mitigation. Secondary effects not included include those on chronic health, on ecosystems, on visibility and traffic accidents, and related quality of life improvements. This will be left for future work.

With respect to data quality, the health evaluations of acute morbidity effects rely on Exposure-Response rates established for the U.S. and Canada and are adjusted by income level for Thailand. This has the potential of over-estimating the effects.

${ }^{15}$ On the extreme side, we observe up to $28 \%$ reduction for the production of basic metal and a $19 \%$ reduction for the production of plastic and rubber. 
Regarding methodology, for the ambient and indoor PM-10 concentration estimations, the study employed an empirical model rather than an air dispersion model. Information on the shares of PM-10 contributions from transportation/construction, industrial, and background sources were acquired from the pollution control division of Thailand. The shares are assumed fixed. Such an approach does not take into account the meteorological factors affecting pollution emitted from the industrial and transportation sources. This could lead to over or underestimation of the ambient average concentration of PM-10.

References:

Anderson, K., and Blackhurst, R. (1992) The Greening of World Tsrade Issues. Ann Arbor: University of Michigan Press.

Armington, P. (1969) A theory of demand for products distinguished by place of production, IMF Staff Papers, 16, 159-78.

Birdsall, N., and Wheeler, D. (1992) "Trade Policy and Industrial Pollution in Latin America: Where Are the Pollution Havens?" in International Trade and the Environment (P. Low, Ed.). World Bank Discussion Paper No. 159. Washington: the World Bank.

Braga, C.A.P. (1992) Tropical Forests and Trade Policy: The Case of Indonesia and Brazil. In International Trade and the Environment (P.Low, Ed.). World Bank Discussion Paper No. 159. Washington: The World Bank.

Burtraw, Dallas and Michael Toman (2000). "Ancillary Benefits of Greenhouse Gas Mitigation Policies,” Climate Change Issues Brief No. 7. Resources for the Future, Washington, D.C.

Chestnut, Lauraine G., Bart D. Ostro, Nuntavarn Vichit-Vadakan, Adit Laixuthai, Wichai Aekplakorn, Kirk R. Smith, and Feng C. Tsai (March 1998). Executive Summary: Health Effects of Particulate Matter Air Pollution in Bangkok. Prepared for Air Quality and Noise Management Division, Pollution Control Department. Bangkok, Thailand.

Copeland, B.R., and Taylor, S.M. (1993) "Trade and Transboundary Pollution," University of British Columbia Discussion Paper, No 93-42.

Copeland, B.R., and Taylor, S.M. (1994) "North-South Trade and the Environment," Quarterly Journal of Economics 109:755-787.

Copeland, B.R., and Taylor, S.M. (1995). Trade and the Environment: A Partial Synthesis. American Journal of Agricultural Economics 77:765-771. 
Cropper, Maureen L. and Frances G. Sussman (September, 1990) "Valuing future risks to life,” Journal of Environmental Economics and Management, Vol. 19 (2):160175.

Dervis, Kemal, Jaime de Melo, and Sherman Robinson. 1982. General Equilibrium Models for Development Policy. Cambridge University Press, 1982. Reprinted by the World Bank, 1989.

Dessus, Sebastien and Maurizio Bussolo (1998). “Is There A Trade-off Between Trade Liberalization and Pollution Abatement?” Journal of Policy Modeling 20(1): 11-31.

EIAa, Emissions of Greenhouse Gases In the United States, http://www.eia.doe.gov/oiaf/1605/1605aold.html

EIAb, Assumptions to the Annual Energy Outlook 201 - Table 2. Carbon Dioxide Emission Factors, http://www.eia.doe.gov/oiaf/aeo/assumption/tb12.html

Food Market Exchange, 2001. "Thailand's Proposal for the Fourth WTO Ministerial Conference: A Clear-cut Agenda," http://www.foodmarketexchange.com/datacenter/laws/detail/dc_1r_reference_Do ha.htm

Garbaccio, Richard F., Mun S. Ho, and Dale W. Jorgenson (2000). "Modeling the Health Benefits of Carbon Emissions Reductions in China,” Preliminary Draft. Kennedy School of Government, Harvard University, Cambridge, MA.

Hettige, H., Lucas, R.E.B., and Wheeler, D. (1992). "The Toxic Intensity of Industrial Production: Global Patterns, Trends and Trade Policy,” American Economic Review, vol. 82.

Lee, H., and Roland-Holst, D. International Trade and the Transfer of Environmental Cost and Benefits. In Applied Trade Policy Modeling (J. Francois and K. Reinert, Eds.). Cambridge: Cambridge University Press, forthcoming.

Lluch, C. (1973), "The Extended Linear Expenditure System", European Economic Review, Vol. 4.

Lofgren, Hans, Rebecca Lee Harris, and Sherman Robinson, with the assistance of Marcelle Thomas and Moataz El-Said (May 2001). "A Standard Computable General Equilibrium (CGE) Model in GAMS,” Discussion Paper No. 75, Trade and Macroeconomics Division, International Food Policy Research Institute.

Low, P., and Yeats, A. (1992). “Do Dirty Industries Migrate?” in International Trade and the Environment (P. Low, Ed.). World Bank Discussion Paper No. 159. Washington: the World Bank.

Mahidol University, (1998).

http://www.mahidol.ac.th/Thailand/economy/charac-econ.html 
Methakunavut, Nuntaporn and Somchai Jitsuchon (2001). Productivity Growth and External Accounts in a Computable General Equilibrium Model. Memio.

OECD (1993.) Environmental Policies and Industrial Competitiveness. Paris: OECD Documents.

Pearce, David (1996). "Economic Valuation and Health Damage from Air Pollution in the Developing World,” Energy Policy. Vol. 24 No. 7: 627-30.

Perroni, C., and Wigle, R.M. (1994). International Trade and Environmental Quality: How Important Are the Linkages? Canadian Journal of Economics 27:551-567.

Rosendahl, Knut Einar (1998). "Health Effects of Air Pollution and Impacts on Economic Activity," in Social Costs of Air Pollution and Fossil Fuel Use - A Macroeconomic Approach. Knut Einar Rosendahl (ed.)

TDRI (20000). “The Construction of Computable General Equilibrium,” a paper submitted to Naitonal Economic and Social Development Board (NESDB). (in Thai)

Thanh, Bui Duy, and Theirry Lefevre. (2000). "Assessing Health Impacts of Air Pollution from Electricity Generation: the Case of Thailand," Environmental Impact Assessment Review, 20: 137-58

Tobey, J.A. (1990). "The Effects of Domestic Environmental Policies on Patterns of World Trade: An Empirical Test,” Kyklos 43: 191-210.

Warr, Peter G. (1998). "Estimation of Elasticity of Substitution/ Transformation between Domestic and Imported/ Exported Commodities,” Australian National University (ANU). 


\section{Appendix 1. Dimensions of the 1998 Thailand}

\begin{tabular}{|c|c|}
\hline \multicolumn{2}{|l|}{ Production sectors } \\
\hline \multicolumn{2}{|l|}{ Non-Energy } \\
\hline AGRIC & Agricultural sectors ${ }^{16}$ \\
\hline ENERINT & Energy intensive industries ${ }^{17}$ \\
\hline OTHRIND & Other industries and services ${ }^{18}$ \\
\hline \multicolumn{2}{|l|}{ Energy } \\
\hline COAL.LIG & Coal and lignite ${ }^{19}$ \\
\hline LPG & Liquefied Petroleum Gas \\
\hline PTRO.GAS & Crude petroleum and natural gas \\
\hline GASOLNE & Gasoline \\
\hline DEISEL & Diesel \\
\hline AVIFUEL & Aviation fuel \\
\hline FUEOIL & Fuel oil \\
\hline ELEC & Electricity \\
\hline \multicolumn{2}{|l|}{ Transportation } \\
\hline TRANLD & Transportation on land \\
\hline TRANOC & Transportation at sea \\
\hline TRANWR & Transportation on water \\
\hline TRANAR & Transportation in the air \\
\hline TRANOT & Other Transportation \\
\hline \multicolumn{2}{|l|}{ Primary Factors } \\
\hline \multicolumn{2}{|l|}{ Labor } \\
\hline \multicolumn{2}{|c|}{ Capital (Agricultural and Non-Agricultural) } \\
\hline \multicolumn{2}{|l|}{ Institutions } \\
\hline \multicolumn{2}{|c|}{$\begin{array}{l}\text { Households (3: Agricultural, Non-Agricultural, Public } \\
\text { Hired) }\end{array}$} \\
\hline \multicolumn{2}{|l|}{ Public Enterprise } \\
\hline \multicolumn{2}{|c|}{ Private Enterprise (all the producer sectors) } \\
\hline \multicolumn{2}{|c|}{ Government } \\
\hline ROW & \\
\hline
\end{tabular}

\footnotetext{
${ }^{16}$ Includes 7 sectors: paddy rice, other crops, vegetables and fruit, other agricultural, livestock, fishing, and forest.

${ }^{17}$ Include basic chemical, land transport, fishing, textile, plastic and rubber, machinery, apparel, non-metal products, basic metal, and air transport.

${ }^{18}$ These include other mining, food, processed food, beverages, tobacco products, leather \& footwear, wood products, printing \& publishing, fabricated metal, industrial, transport equipment, water supply, construction, wholesale \& retail, ocean transportation, water transportation, and business service.

${ }^{19}$ A brownish-black coal of low rank with high inherent moisture and volatile matter content, used almost exclusively for electric power generation. Also referred to as brown coal (http://www.eia.doe.gov/oiaf/1605/87-92rpt/glossary.html\#Fossil_fuel).
} 


\section{Appendix 2:}

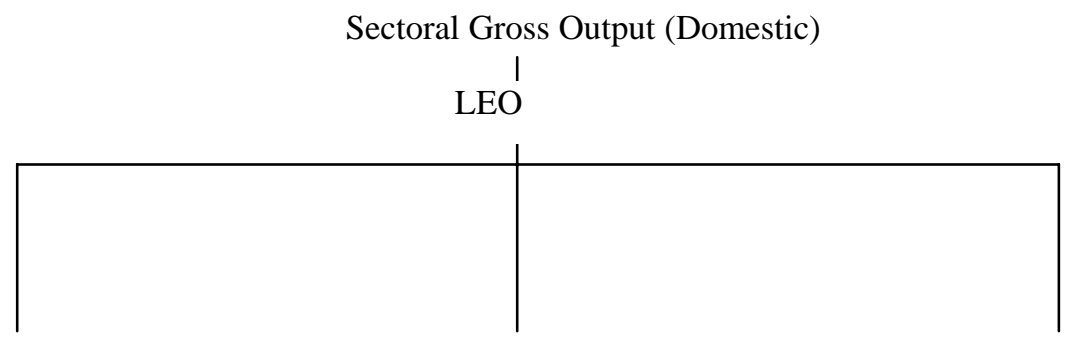

Non-Energy Intermediate Input Bundle

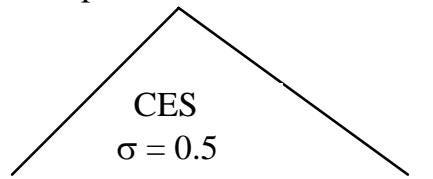

Cpaddy, Ccrop, ... (53 total)
Energy-Intermediate Input Bundle

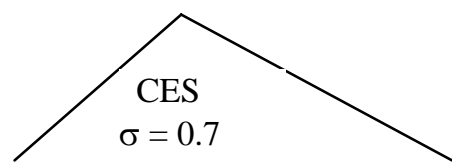

COAL, GAS, OIL ....(8 total)

\section{Labor-Capital Bundle}

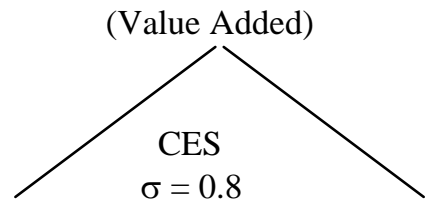

L , Agr Cap, Non-Agr Cap (3 total) 
Appendix 3: From Source term to PM-10 Concentration Calculation Flowchart

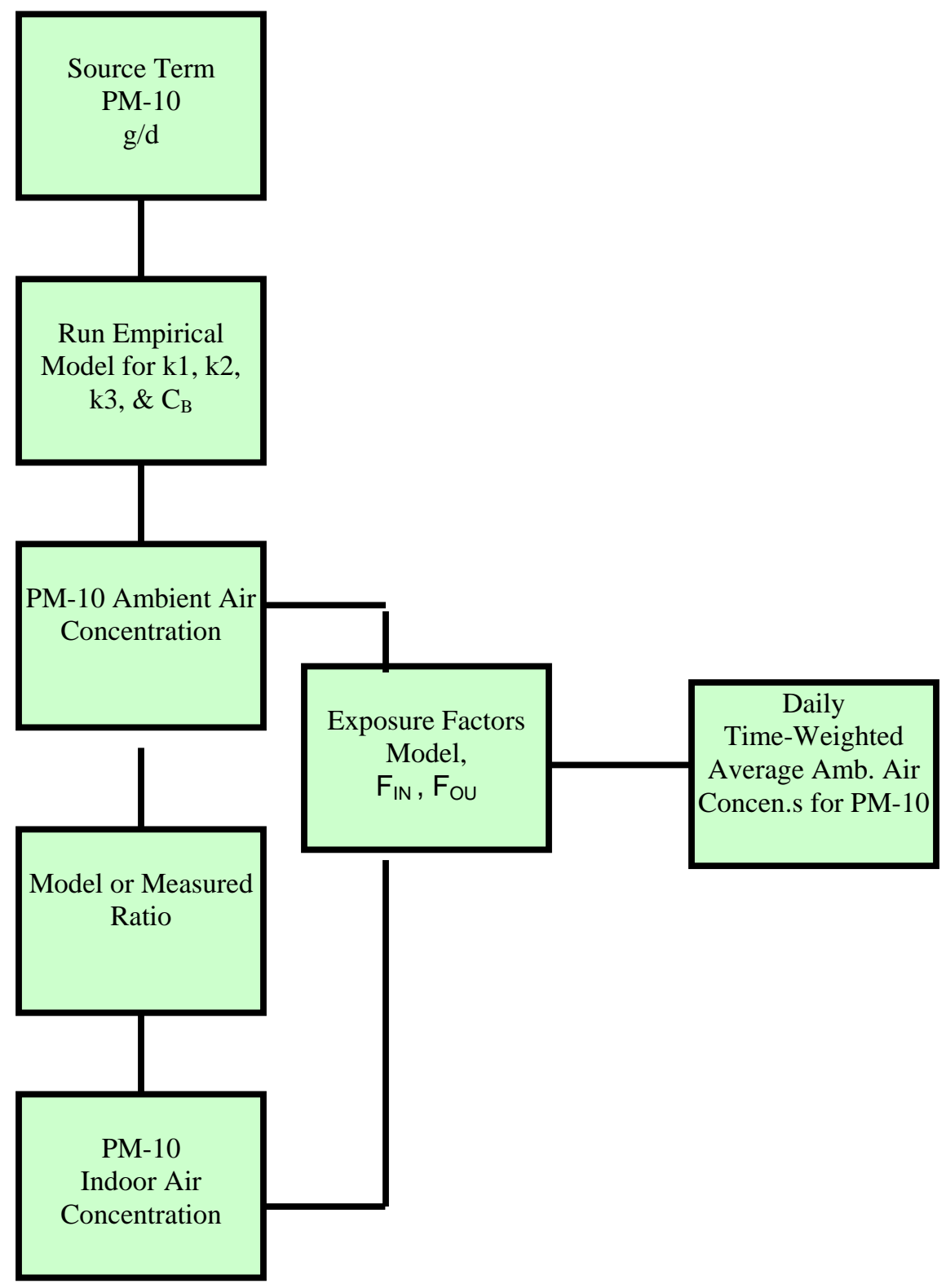

